\title{
$\angle$ Research Square \\ Differences in the effect of sleep deprivation on the postural stability among men and women
}

\author{
Marta Ołpińska-Lischka ( $\nabla$ m.olpinska.lischka@tlen.pl) \\ 0001-5079-4548

\section{Karolina Kujawa} \\ Akademia Wychowania Fizycznego im Eugeniusza Piaseckiego w Poznaniu \\ Janusz Maciaszek ( $\nabla$ jmaciaszek@awf.poznan.pl) \\ Akademia Wychowania Fizycznego im Eugeniusza Piaseckiego w Poznaniu
}

Akademia Wychowania Fizycznego im Eugeniusza Piaseckiego w Poznaniu https://orcid.org/0000-

\section{Research}

Keywords: sleep deprivation, postural control, posturography, gender difference

Posted Date: August 18th, 2020

DOl: https://doi.org/10.21203/rs.3.rs-48565/v2

License: (9) This work is licensed under a Creative Commons Attribution 4.0 International License. Read Full License

Version of Record: A version of this preprint was published at International Journal of Environmental Research and Public Health on April 5th, 2021. See the published version at https://doi.org/10.3390/ijerph18073796. 
The authors have withdrawn this preprint from Research Square 